\title{
Co-disposição de lodo centrifugado de Estação de Tratamento de Água (ETA) em matriz de concreto: método alternativo de preservação ambiental
}

\section{(Disposal of centrifuged sludge from Water Treatment Plant (WTP) in concrete matrix: an alternative method for environmental protection)}

\author{
C. Hoppen ${ }^{1}$, K. F. Portella', A. Joukoski', O. Baron ${ }^{2}$, R. Franck',

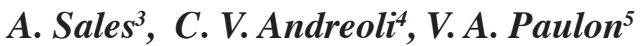 \\ ${ }^{1}$ Centro Politécnico, Universidade Federal do Paraná, Curitiba, PR 81531-980 \\ ${ }^{2}$ DPMA, Instituto de Tecnologia para o Desenvolvimento, C. P. 19067, Curitiba, PR 81531-980 \\ ${ }^{3}$ DECIV, Universidade Federal de S. Carlos, Rod. Washington Luiz, km 235, S. Carlos, SP 13565-905 \\ ${ }^{4}$ APD, Companhia de Saneamento do Paraná, R. Engenheiro Rebouças 1376, Curitiba, PR 80215-900 \\ ${ }^{5}$ FEC, Universidade Estadual de Campinas, C. P. 6021, Campinas, SP 13083-852 \\ portella@lactec.org.br
}

\begin{abstract}
Resumo
O crescimento da demanda por água potável tem implicado em um aumento da quantidade de resíduos nas estações de tratamento de água (ETA). Apesar destes terem sido gerados por processo erosivo do solo nos mananciais que antecedem as ETAs, o tratamento químico requerido para a sua remoção obriga a uma disposição correta para não impactar, negativamente, o meio ambiente. Até agora, o destino mais comum para o lodo de ETA são os cursos d'água, mesmo ele sendo considerado um resíduo sólido. Neste trabalho, é proposta alternativa de co-disposição deste resíduo, ainda úmido, em matrizes de concreto, substituindo-se parcialmente seus insumos: os agregados miúdos e o cimento, cuja extração e emprego também causam impacto ambiental. Inicialmente, caracterizaram-se os insumos do concreto (cimento Portland CPII-F 32, areia e brita), além do lodo extraído da ETA Passaúna, localizada na região metropolitana de Curitiba. Para os estudos de dosagem, utilizou-se um concreto-referência (sem adição de lodo) e traços de concreto com teores de 3, 5, 7 e $10 \%$ de lodo em relação ao peso de areia e em substituição à mesma. Nos concretos resultantes foram avaliadas propriedades tanto no estado fresco quanto no endurecido. O lodo é constituído, praticamente, de compostos de $\mathrm{Si}, \mathrm{Al}$ e $\mathrm{Fe}$, e do argilomineral do grupo caulinita, tendo teor de umidade em torno de $87 \%$. Nos ensaios de resistência à compressão, as dosagens até $5 \%$ apresentaram um $\mathrm{f}_{c 28}$ maior que $25 \mathrm{MPa}$. Para as dosagens com teores de lodo superiores a $5 \%, \mathrm{of}_{\mathrm{c} 28}$ foi menor, principalmente, para a dosagem de $10 \%$. A análise dos dados permite concluir que os traços com até $5 \%$ de lodo podem ser aplicados em situações que vão desde a fabricação de artefatos e blocos até a construção de pavimentos em concreto de cimento Portland. Em relação às misturas com teores acima de 5\%, a sua utilização é restrita a aplicações em que a trabalhabilidade não é um parâmetro primordial, como contrapisos, calçadas e pavimentos residenciais.
\end{abstract}

Palavras-chave: concreto, co-disposição, lodo de ETA, caracterização.

Abstract

The increase in the demand for drinking water implies in an increase in sludge production in Water Treatment Plants (WTP). Despite the fact that this residue is generated by soil erosion in upstream locations, the required chemical treatment for its removal compels to correct disposal in order not to induce negative impact on the environment. So far, the common destination for the sludge is the river courses, even though it is classified as solid residue. In this work, an alternative disposal of the humid sludge in concrete matrixes is proposed, partially replacing fine aggregates (sand) and cement, whose extraction and application also cause environmental impact. Initially, the materials used in concrete (filler-modified Portland cement, fine and coarse aggregates) were characterized, as well as the sludge obtained from Passauna WTP, located in Curitiba's metropolitan area. For the materials research, a reference concrete (with no addition of sludge) and four concrete mixtures with sludge contents of 3, 5, 7 and $10 \mathrm{wt} . \%$ (replacing fine aggregate) were produced. The properties of fresh and hardened concretes, including the compressive strength, were evaluated. The sludge is composed by Si, Fe and Al compounds, and by clay minerals of kaolinite group, and its moisture content is about 87\%. In compressive strength testing, the mixtures containing up to 5\% of sludge presented $a f_{c 28}$ higher than $25 \mathrm{MPa}$. For sludge contents over $5 \%, f_{c 28}$ was lower, especially for the concrete with $10 \%$ waste. It could be concluded that the mixtures with up to $5 \%$ sludge from WTP can be employed in applications ranging from the manufacture of concrete artifacts and bricks to the construction of Portland cement concrete floors. On the order hand, the use of more than 5\% sludge in concrete is restricted to applications where the workability of concrete is not a required parameter, such as residential pavements, sidewalks and floors.

Keywords: concrete, disposal, sludge from water treatment plant, characterization. 


\section{INTRODUÇÃO}

O crescimento das cidades e os constantes esforços pelo aumento da qualidade de vida dos seus cidadãos têm aumentado a demanda por água tratada e, assim, a quantidade de materiais sólidos provenientes do tratamento das águas fluviais nas estações de tratamento de água (ETA) [1]. Estes materiais, chamados lodos de ETA ou lodos de água, são classificados como "resíduos sólidos" e devem ser tratados e dispostos corretamente segundo norma brasileira correspondente [2], tal como nos Estados Unidos e em outras comunidades mundiais [3].

O lodo de ETA tem sua origem, na maioria das vezes, nos decantadores e representa de 0,3 a $1,0 \%$ do volume de água tratada. Contém materiais inertes, matéria orgânica e precipitados químicos, incluindo compostos de alumínio ou ferro em grande quantidade, dependendo do tipo de tratamento utilizado e da própria ETA [4-7]. É, comumente, obtido com coagulantes à base de sulfato de alumínio ou cloreto férrico. Este último apresenta, normalmente, maior concentração de metais, estando os teores médios de $\mathrm{Cr}, \mathrm{Cu}, \mathrm{Ni}, \mathrm{Pb}$ e $\mathrm{Zn}$ acima dos demais elementos químicos [8]. Na Tabela I, é verificada a concentração dos metais encontrados em três diferentes ETAs do Estado de São Paulo, sugerindo que o local de coleta, o tipo de tratamento e o coagulante utilizado são importantes na contaminação final do resíduo [3].

No Paraná, a cada mês, são produzidas, aproximadamente, 4.000 toneladas de matéria seca de lodo de ETA. A produção deste material na cidade de Curitiba corresponde a mais de $50 \%$ de todo o Estado, sendo que a ETA Passaúna, localizada na região metropolitana e objeto de estudo deste trabalho, produz cerca de 360 toneladas por mês.

\section{Disposição final do lodo de ETA}

Segundo a referência [9], uma das tarefas mais difíceis para o serviço de tratamento de água é o destino final do lodo, pois envolve custos de manuseio e transporte e restrições ambientais. Dentre as opções disponíveis para a disposição do material, destacam-se: lançamento em cursos d'água, aplicação no solo, disposição em aterro sanitário, incineração, fabricação de cimento e tijolos, e reciclagem em matriz de concreto.
O lançamento em cursos d'água pode ser feito sob certas condições e depende de permissão dos órgãos ambientais. Esta autorização é função das características e do volume do curso d'água. Existem restrições a esta prática devido à possibilidade de se alterar a biota aquática e de se causar degradação da água e sedimentos, pela presença de contaminantes nos coagulantes utilizados $[9,10]$.

A aplicação no solo consiste em esparramar o lodo em terreno natural ou em solos agricultáveis. Esta prática vem sendo considerada uma alternativa de disposição viável para os casos em que não é comprovada a existência de impactos negativos no solo receptor $[5,9$, 11]. Algumas desvantagens dessa solução são devidas às altas concentrações de alumínio no lodo e sua tendência em fixar o fósforo ao solo, tornando inapropriado o crescimento das plantas. Além disso, devido a contaminantes no coagulante, este lodo pode conter elevadas concentrações de $\mathrm{Pb}, \mathrm{Cr}, \mathrm{Cd}$, dentre outros metais, provocando a degradação local $[12,13]$.

O despejo em aterro sanitário ainda se apresenta como alternativa viável para a disposição final, apesar de seu custo elevado e das implicações ambientais decorrentes do mesmo [9]. Nos EUA, dentro das práticas de disposição do lodo, o aterro municipal é adotado em, aproximadamente, $20 \%$ das cidades com até 100.000 habitantes [6].

Para a incineração, os custos referentes a esta alternativa são bastante altos, além de resultar em cinzas que também necessitam de disposição adequada ou incorporação em um outro tipo de produto, apenas transferindo o problema [11].

Uma vez que os principais componentes do cimento Portland: $\mathrm{Ca}, \mathrm{Si}, \mathrm{Al}$ e $\mathrm{Fe}$ são, também, encontrados nos lodos de ETA, estes podem ser empregados na produção de argamassas, artefatos e blocos de concreto para a construção civil, substituindo, em até certas proporções, as matériasprimas normalmente utilizadas [9]. Considerando que o setor da construção civil é o maior consumidor individual de recursos naturais, demandando de 20 a $50 \%$ do total de insumos extraídos, a reciclagem de lodo em concretos pode ser uma alternativa para a diminuição de impactos ambientais. Em se tratando da produção de tijolos, determinadas

Tabela I - Concentrações de metais (mg.L-1) encontrados nos lodos de três ETAs do Estado de S. Paulo [3].

[Table I - Metal contents ( $\left.m g . L^{-1}\right)$ found in the sludge from three S. Paulo's WTP [3].]

\begin{tabular}{cccc}
\hline Parâmetros & ETA S. Carlos & ETA Araraquara & ETA Rio Claro \\
\hline Alumínio & $11.100,00$ & 2,16 & 30,00 \\
Zinco & 4,25 & 0,10 & 48,53 \\
Chumbo & 1,60 & 0,00 & 1,06 \\
Cádmio & 0,02 & 0,00 & 0,27 \\
Níquel & 1,80 & 0,00 & 1,16 \\
Ferro & $5.000,00$ & 214,00 & $4.200,00$ \\
Manganês & 60,00 & 3,33 & 30,00 \\
Cobre & 2,06 & 1,70 & 0,09 \\
Cromo & 1,58 & 0,19 & 0,86 \\
\hline
\end{tabular}


concentrações de lodo na massa podem prejudicar as características finais e dificultar o processamento [14].

Alguns pesquisadores [15], estudando a reciclagem secundária de lodo seco em matriz de concreto, pela avaliação da resistência mecânica à compressão e do teor de absorção de água, concluíram sobre a sua viabilidade em aplicações não-estruturais na construção civil.

De forma a ampliar as alternativas de disposição do lodo de ETA e conhecer a maioria das propriedades usuais do concreto obtido, verificou-se neste e em outro trabalho [16], a possibilidade de sua incorporação em concreto, na forma in natura, ou seja, como obtido da centrífuga, eliminando-se a etapa de secagem e seus custos relativos.

\section{EXPERIMENTAL}

O procedimento experimental foi feito em três etapas: caracterização das matérias-primas (areia, brita 1, cimento e lodo de ETA); estudos de dosagem para a qualificação e seleção de cinco traços de concreto, sendo quatro destes com diferentes teores de lodo em relação ao peso seco da areia e um traço padrão (concreto-referência), sem a adição de lodo; e, por último, a avaliação das propriedades das misturas no estado fresco e o desempenho dos concretos no estado endurecido.

\section{Agregados}

Os agregados utilizados na confecção de concretos foram a areia natural média lavada e a pedra britada $n^{\circ} 1$ (dimensão máxima característica de $19 \mathrm{~mm}$ ). Os principais parâmetros físicos dos agregados graúdos e miúdos foram analisados seguindo recomendações das normas brasileiras [17-25]. Além destas determinações, foram realizadas caracterização química por fluorescência de raios X (FRX), Philips PW2400, e análise petrográfica, por meio de microscopia óptica com luz polarizada, com o intuito de identificar sua natureza geológica.

\section{Aglomerante}

Utilizou-se cimento Portland composto com adição de fíller e $\mathrm{f}_{\mathrm{c} 28}=32 \mathrm{MPa}$ (CPII-F 32), cuja caracterização foi feita segundo recomendações das normas brasileiras e de outros trabalhos [26-40].

\section{Lodo de ETA}

O material foi coletado na ETA Passaúna, localizada na região metropolitana de Curitiba. Esta ETA possui capacidade para tratar 2.400 L.s ${ }^{-1}$ de água, sendo que, neste tratamento, utilizam-se sulfato de alumínio, flúor e fosfato nas diversas etapas inerentes ao processo. Além desses produtos, são adicionados polímeros com a finalidade de aumentar a eficiência da centrífuga utilizada no processo de adensamento do lodo. $\mathrm{O}$ lodo foi coletado na saída da centrífuga, sem nenhum tratamento posterior para a sua co-disposição no concreto. De forma a se obter uma amostra de lodo representativa, foram realizadas coletas diárias de, aproximadamente, $2 \mathrm{~kg}$ de material, durante dois meses, ao término dos quais as partes foram misturadas e homogeneizadas, obtendo-se uma amostra única que foi caracterizada físico-quimicamente e empregada na fabricação dos concretos.

Análise termogravimétrica (TG) de amostras de lodo seco pulverizado foi feita no intervalo de temperatura entre $25^{\circ} \mathrm{C}$ e $1000{ }^{\circ} \mathrm{C}$, com o objetivo de determinar tanto a variação de massa quanto a variação de calor correspondente. Utilizou-se equipamento Netzsch STA 409 em cadinho aberto de platina, sob atmosfera de $\mathrm{O}_{2}$ e $\mathrm{N}_{2}$, e taxa de aquecimento do forno de $10^{\circ} \mathrm{C} / \min [16]$.

A identificação das fases químicas dos materiais foi verificada pela difração de raios X (DRX). As amostras foram preparadas pela conformação em porta-amostra do equipamento, no seu estado in natura e após pré-secagem do lodo em estufa, a $110{ }^{\circ} \mathrm{C}$, por $12 \mathrm{~h}$. Também, no caso do lodo, foi adotado o procedimento para identificação dos argilominerais [41], e que consiste na separação, por suspensão aquosa, da fração argila do material, e posterior secagem orientada em lâmina de vidro. A identificação é feita pela medida da distância interplanar basal do argilomineral. Os parâmetros de análise utilizados foram: radiação $\mathrm{Cu} \mathrm{K \alpha}$, com comprimento de onda 1,54184 $\AA$; tensão $40 \mathrm{kV}$; corrente $40 \mathrm{~mA}$; varredura $2 \theta$ entre $5^{\circ}$ e $90^{\circ}$; passo $0,020^{\circ}$; tempo do passo $1 \mathrm{~s}$; velocidade de varredura $0,020^{\circ} \cdot \mathrm{s}^{-1}$.

A composição química dos insumos foi obtida por FRX e também por espectrofotometria de absorção atômica com atomização em chama, em um espectrofotômetro Perkin Elmer, modelo 4100.

\section{Dosagens}

Antes do início das dosagens, foram feitas determinações da umidade dos agregados naturais. Os valores obtidos foram levados em consideração no cálculo do peso de água adicionada na massa.

Para a mistura dos concretos utilizou-se uma betoneira, previamente "imprimada" (preparada para a operação), com capacidade nominal de 120 L e rotação do tambor de $28 \mathrm{rpm}$, sendo que, em cada amassada, foi utilizado um volume total de mistura de $25 \mathrm{~L}$. Primeiramente, foram adicionados os agregados graúdos, seguidos dos agregados miúdos e metade da água (ou da mistura água + lodo) prevista. A betoneira foi então acionada por $30 \mathrm{~s}$, a fim de promover a mistura entre a areia e a brita. Então, adicionou-se o cimento e o restante da água (ou da mistura água + lodo). $\mathrm{O}$ amassamento do concreto deu-se em três etapas totalizando um tempo de $8 \mathrm{~min}$.

Os principais fatores considerados para o desenvolvimento das dosagens foram a trabalhabilidade no estado fresco e a resistência mecânica à compressão axial do material no estado endurecido, em função da quantidade de lodo úmido (in natura) adicionado a um concreto-referência. 


\section{Concreto-Referência}

Os parâmetros adotados para a confecção do concretoreferência estão listados na Tabela II.

A proporção entre os agregados foi definida a partir de determinações expeditas do teor ideal de areia, em função da trabalhabilidade, módulo de finura e fator água/cimento (a/c). Este último foi escolhido tendo-se como base os valores comumente verificados na literatura nacional referente a artefatos de concreto para redes de distribuição de energia. Já a definição da relação cimento/agregados foi baseada na obtenção de um concreto de referência que apresentasse um consumo de cimento da ordem de $350 \mathrm{~kg} \cdot \mathrm{m}^{-3}$, já que este traço poderá ser utilizado popularmente e sem considerações estatísticas quanto ao desvio padrão da resistência mecânica à compressão [42].

A consistência dos concretos, expressa pela medida do abatimento do tronco de cone (slump), foi deixada livre, de forma que pudesse ser um dos parâmetros variáveis a serem avaliados em função do teor de lodo de ETA adicionado.

Tabela II - Parâmetros de dosagem para o concreto de referência.

[Table II - Mixture parameters for the reference concrete.]

\begin{tabular}{lc}
\hline \multicolumn{1}{c}{ Parâmetro de dosagem } & Valor \\
\hline Fator água/cimento (a/c) & 0,5 \\
Teor de agregados miúdos & $40,4 \%$ \\
Teor de agregados graúdos & $59,6 \%$ \\
Relação cimento/agregados totais & $0,2($ ou $1: 5)$ \\
Teor de lodo & $0 \%$ \\
\hline
\end{tabular}

\section{Concreto com lodo de ETA}

Para este estudo foram adotados os mesmos parâmetros utilizados no concreto-referência, de forma a ser possível uma correlação entre as propriedades de todos os traços dosados. Foram fabricados quatro concretos incorporando o lodo de ETA in natura, em teores de 3\%, 5\%, 7\% e 10\% do peso de agregado miúdo e em substituição a este. A quantidade de água de amassamento, em cada traço, foi corrigida em função da massa e do teor de umidade do lodo acrescentado. Para a adição do lodo, procedeu-se à mistura do mesmo na água de amassamento prevista, com o auxílio de um misturador helicoidal.

\section{Propriedades do concreto fresco}

A cada dosagem, foram realizados ensaios para determinação das seguintes características: medida do slump, massa unitária, teor de ar incorporado e temperatura da mistura, com base nos procedimentos de norma [43-45].

\section{Moldagem dos corpos-de-prova}

Para cada concreto fabricado, foram moldados 6 corposde-prova (cp's) cilíndricos de $10 \mathrm{~cm}$ de diâmetro e $20 \mathrm{~cm}$ de altura, destinados ao ensaio para determinação da resistência mecânica à compressão axial, aos $7 \mathrm{~d}$ e aos $28 \mathrm{~d}$. A moldagem dos cp's seguiu as recomendações da NBR 5738/94 [46].

\section{Resistência à compressão axial simples}

Ao completarem-se as idades previstas para os ensaios (7 e 28 d), os cp's de cada dosagem, após terem sido capeados com enxofre, foram levados à ruptura por compressão axial simples, observando-se os procedimentos recomendados pela norma NBR 5739/94 [47]. Até a data do rompimento, os cp's foram mantidos sob cura em câmara úmida a $(23 \pm 2){ }^{\circ} \mathrm{C}$ e umidade relativa mínima de $95 \%$.

Para as rupturas, utilizou-se máquina universal de ensaios com capacidade de carga de 100 ton.

\section{Ensaios físicos em amostras de concreto}

Dos cp's de concreto, rompidos no ensaio de compressão axial aos $28 \mathrm{~d}$, foram extraídas amostras para determinação do teor de absorção de água por imersão, massa específica e índice de vazios dos concretos endurecidos, seguindo-se as recomendações da norma NBR 9778/87 [48].

\section{RESULTADOS E DISCUSSÃO \\ Agregados}

Somente os resultados quanto ao teor de material pulverulento da areia não estão em conformidade com a norma NBR 7218/87 [18], que recomenda teores máximos de 3,0\%. Entretanto, os valores verificados de $3,2 \%$ não comprometem a qualidade do concreto fabricado com este agregado.

Ambos os agregados possuem granulometria tipicamente contínua. De acordo com o enquadramento do agregado miúdo nos limites granulométricos normalizados pela NBR 7211/83 [49], o mesmo é caracterizado como areia média, pertencente à zona 3. No caso do agregado graúdo, a faixa que mais se aproxima da sua granulometria é a referente à brita de graduação 1. Na Tabela III, estão inseridos os resultados da análise química por FRX.

Pela composição mineralógica dos agregados, determinada por análise petrográfica, constatou-se que a areia é constituída essencialmente por quartzo, com elevado estágio de recristalização e certo estiramento mineral, sendo que a orientação dos seus cristais indica ser uma rocha metamórfica gerada em um elevado estágio deformacional. A pedra brita 1 foi classificada como quartzo microclínio milonito. Composição mineralógica e características microestruturais similares a esta brita são descritas na literatura como uma indicação de materiais potencialmente reativos $[40,42,50]$.

\section{Cimento}

A composição química resultante é similar ao especificado pelo fabricante. Contudo, o teor de álcalis, pelo 
Tabela III - Resultados da análise química por FRX, efetuada nos agregados.

[Table III - Results of the chemical analysis of aggregates, by XRF.]

\begin{tabular}{ccc}
\hline $\begin{array}{c}\text { Compostos } \\
\text { analisados }\end{array}$ & Areia (\%) & Brita 1 (\%) \\
\hline $\mathrm{SiO}_{2}$ & 90,24 & 71,54 \\
$\mathrm{Al}_{2} \mathrm{O}_{3}$ & 4,34 & 14,91 \\
$\mathrm{TiO}_{2}$ & 0,54 & 0,03 \\
$\mathrm{Fe}_{2} \mathrm{O}_{3}$ & 0,94 & 0,93 \\
$\mathrm{MnO}$ & 0,01 & 0,02 \\
$\mathrm{MgO}$ & 0,24 & 0,18 \\
$\mathrm{CaO}$ & 0,14 & 0,75 \\
$\mathrm{Na}$ & 0,42 & 5,27 \\
$\mathrm{~K}_{2} \mathrm{O}$ & 1,51 & 3,84 \\
$\mathrm{P}_{2} \mathrm{O}_{5}$ & 0,01 & 0,03 \\
$\mathrm{Soma}$ & 98,57 & 97,75 \\
\hline
\end{tabular}

equivalente alcalino $\left(\mathrm{Na}_{2} \mathrm{O}+0,658 . \mathrm{K}_{2} \mathrm{O}\right)$ determinado de 0,81 , é suficiente para proporcionar reações expansivas do tipo álcali-agregado [51-52].

\section{Lodo de ETA}

As análises termogravimétricas do lodo in natura indicaram perda de massa média de $87 \%$, entre $25{ }^{\circ} \mathrm{C}$ e $1000{ }^{\circ} \mathrm{C}$, devido à eliminação de água adsorvida, hidroxilas, decomposição de alguns materiais constituintes e matéria orgânica [41]. Uma das curvas de TG do material estudado está apresentada na Fig. 1.

A massa específica do lodo in natura resultou no valor médio de $(1,06 \pm 0,013) \mathrm{mg} \cdot \mathrm{m}^{-3}$. Este valor está dentro da faixa citada em [9] para um lodo contendo $12 \%$ de sólidos, sendo de $1,03 \mathrm{mg} \cdot \mathrm{m}^{-3}$ a $1,08 \mathrm{mg} \cdot \mathrm{m}^{-3}$.

Similarmente ao que foi constatado na literatura [3, 41], a análise do lodo seco pulverizado, por FRX, revelou a presença de compostos de $\mathrm{Al}$, Si e Fe em maior concentração, conforme mostrado na Tabela IV. Comparando-se tais resultados com os da Tabela I, observa-se que não foram detectados os elementos químicos $\mathrm{Zn}, \mathrm{Pb}, \mathrm{Cd}, \mathrm{Cu}$ e $\mathrm{Cr}$. A concentração destes metais no lodo varia com o local de coleta, ou seja, com o tipo de contaminante na água a ser tratada e com a quantidade destes elementos químicos no agente coagulante utilizado.

As fases químicas nas amostras de lodo in natura, preparadas pela conformação por prensagem no portaamostra do equipamento, não foram detectadas pela técnica de DRX. A identificação destas só foi possível após aplicação do procedimento de sedimentação do material sobre um substrato de vidro, descrito em [41]. A análise do difratograma obtido desta maneira, com auxílio do banco de dados do International Centre for Diffraction Data (ICDD), indicou a presença das fases do argilomineral do grupo caulinita com as reflexões basais [001] a aproximadamente 7 Å. Este argilomineral, também, foi encontrado em outro

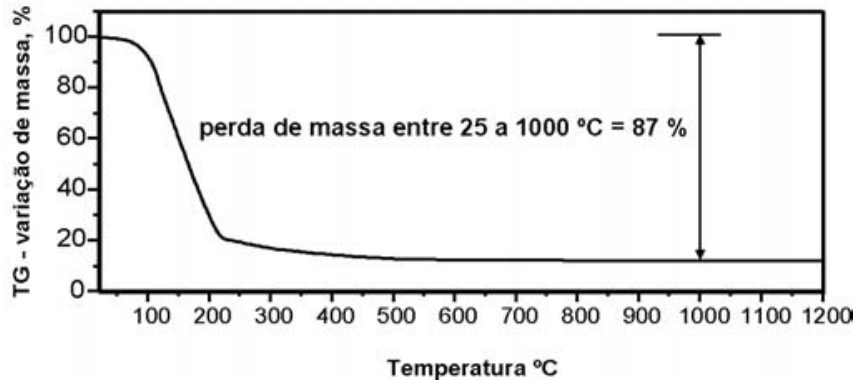

Figura 1: Curva TG do lodo.

[Figure 1: TG curve of sludge.]

Tabela IV - Resultados da análise química do lodo da ETA Passaúna, por FRX.

[Table IV - Results of the chemical analysis of sludge from Passaúna WTP, by XRF.]

\begin{tabular}{cc}
\hline Compostos analisados & Lodo de ETA $(\%)$ \\
\hline $\mathrm{SiO}_{2}$ & 16,55 \\
$\mathrm{Al}_{2} \mathrm{O}_{3}$ & 13,07 \\
$\mathrm{TiO}_{2}$ & 0,19 \\
$\mathrm{Fe}_{2} \mathrm{O}_{3}$ & 4,15 \\
$\mathrm{MnO}$ & 0,22 \\
$\mathrm{MgO}$ & 0,15 \\
$\mathrm{CaO}$ & 0,43 \\
$\mathrm{Na} O$ & 0,04 \\
$\mathrm{~K}_{2} \mathrm{O}$ & 0,06 \\
$\mathrm{P}_{2} \mathrm{O}_{5}$ & 0,26 \\
Perda ao fogo & 49,79 \\
Outros compostos voláteis & 15,09 \\
Soma & 100,00 \\
\hline
\end{tabular}

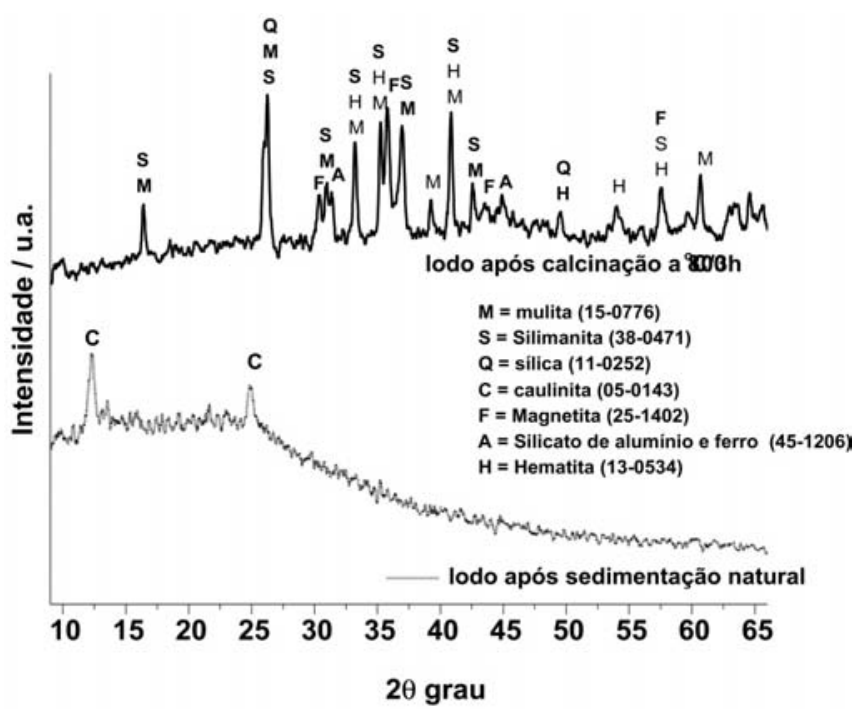

Figura 2: Difratograma de raios X do lodo de ETA, após calcinação e sedimentação natural.

[Figure 2: XRD pattern of sludge, after calcination and sedimentation.] 
trabalho [3], na ETA S. Carlos. Pela calcinação do lodo a $800{ }^{\circ} \mathrm{C}$ foram obtidas e identificadas, pelo banco de dados do ICDD, as fases $\mathrm{Al}_{2} \mathrm{SiO}_{5}, \mathrm{Al}_{6} \mathrm{Si}_{2} \mathrm{O}_{13}, \mathrm{SiO}_{2}, \mathrm{Fe}_{2} \mathrm{O}_{3}$ e $\mathrm{Al}_{0,3} \mathrm{Fe}_{3} \mathrm{Si}_{0,7}$. Ambos difratogramas encontram-se na Fig. 2.

\section{Estudos de dosagem}

$\mathrm{Na}$ Tabela V estão apresentadas as características e os resultados das propriedades medidas nos concretos no estado fresco.

O calor de reação dos concretos contendo lodo é mais exotérmico do que o do concreto-referência; porém, a elevação da temperatura obtida para dosagens com $10 \%$ de lodo ficou inferior a $3{ }^{\circ} \mathrm{C}$, não devendo influenciar no aumento da fissuração, como consequiência de retração mais intensa.

Nas Figs. 3 e 4 estão ilustradas as mudanças que ocorrem nos consumos de cimento e de lodo, respectivamente, em razão da variação do teor de lodo utilizado. À medida que o teor de lodo aumenta de $0 \%$ a $10 \%$ (consumo de lodo de $70 \mathrm{~kg} . \mathrm{m}^{-3}$ ), ocorre uma redução da ordem de $4 \%$ do consumo de cimento, devido à substituição parcial dos materiais (agregados, aglomerante e água de amassamento).

A consistência do concreto, denotada pelo slump, apresentou uma redução bastante expressiva para a mistura com 3\% de lodo. A partir deste teor, o decréscimo foi praticamente linear, até atingir o valor mínimo (abatimento nulo) com a adição de $10 \%$ de resíduo. Isto se deve ao fato do lodo ser constituído por finos que apresentam maior superfície específica que a areia substituída, o que aumenta a absorção de água e reduz a trabalhabilidade do concreto.

As misturas com $7 \%$ e $10 \%$ de lodo mostraram grande dificuldade no seu adensamento, mesmo com a utilização de vibradores de imersão, em virtude da sua elevada consistência (abatimentos de $6 \mathrm{~mm}$ e $0 \mathrm{~mm}$, respectivamente). Nestes casos, foi necessário o adensamento em mesa vibratória. A principal desvantagem está no aumento do custo de produção dos concretos.

Considerando-se, unicamente, o critério de trabalhabilidade, podem-se direcionar as misturas com até $5 \%$ de lodo para aplicação em blocos, peças e artefatos de concreto, inclusive de geometrias mais complexas, pois não há necessidade de vibradores mecânicos. Acima desse teor, o concreto é mais indicado para aplicações que não dependam de adensamento manual e cujo formato não apresente complexidade.

A massa unitária do concreto com lodo diminuiu em cerca de $4 \%$ em relação ao concreto-referência, o que demonstra uma pequena redução de peso deste material com a adição. Isto se deve à menor massa específica do lodo, cujo valor é cerca de $40 \%$ da densidade do agregado miúdo por ele substituído.

O teor de ar incorporado também diminuiu com o incremento do teor de lodo. Apesar da redução relativa total ter sido de, aproximadamente, $60 \%$, isto não tem influência considerável

Tabela V - Características e propriedades dos concretos frescos.

[Table V-Characteristics and properties of the fresh concrete.]

\begin{tabular}{lccccc}
\hline Teor de lodo (\% peso de areia) & $0 \%$ & $3 \%$ & $5 \%$ & $7 \%$ & $10 \%$ \\
\hline Dosagem & E-1038 & E-1108 & E-1109 & E-1111A & E-1110 \\
\hline Temperatura do concreto $\left({ }^{\circ} \mathrm{C}\right)$ & 18,3 & 19,0 & 19,5 & 20,3 & 21,2 \\
\hline Traço & & & & & \\
Cimento & 1 & 1 & 1 & 1 & 1 \\
Areia média & 2,02 & 1,96 & 1,92 & 1,88 & 1,82 \\
Brita 1 & 2,98 & 2,98 & 2,98 & 2,98 & 2,98 \\
$\quad$ Lodo de ETA & - & 0,06 & 0,10 & 0,14 & 0,20 \\
\hline Consumos (mg.m $\left.{ }^{-3}\right)$ & & & & & \\
Cimento & 364 & 356 & 355 & 352 & 349 \\
Areia média & 736 & 698 & 682 & 662 & 636 \\
Brita 1 & 1.085 & 1.061 & 1.058 & 1.049 & 1.041 \\
Água & 183 & 178 & 178 & 177 & 175 \\
Lodo de ETA & - & 22 & 36 & 50 & 70 \\
\hline Slump (mm) & 65 & 17 & 10 & 06 & 00 \\
\hline Massa unitária $\left(\mathrm{kg} . \mathrm{m}^{-3}\right)$ & & & & & \\
Teórica & 2.373 & 2.345 & 2.326 & 2.307 & 2.280 \\
Real & 2.366 & 2.319 & 2.305 & 2.293 & 2.268 \\
\hline Ar incorporado (\%) & & & & & \\
Teórico & 0,3 & 1,1 & 0,9 & 0,6 & 0,5 \\
Real & - & 2,0 & 1,5 & 1,5 & 1,0 \\
\hline
\end{tabular}




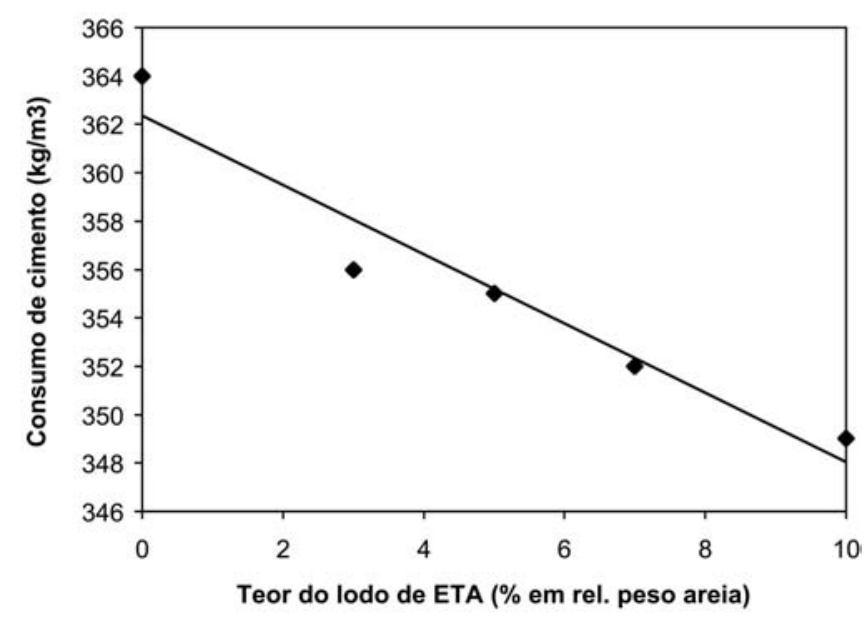

Figura 3: Consumo de cimento em função do teor de lodo.

[Figure 3: Cement consumption as a function of the sludge content.]

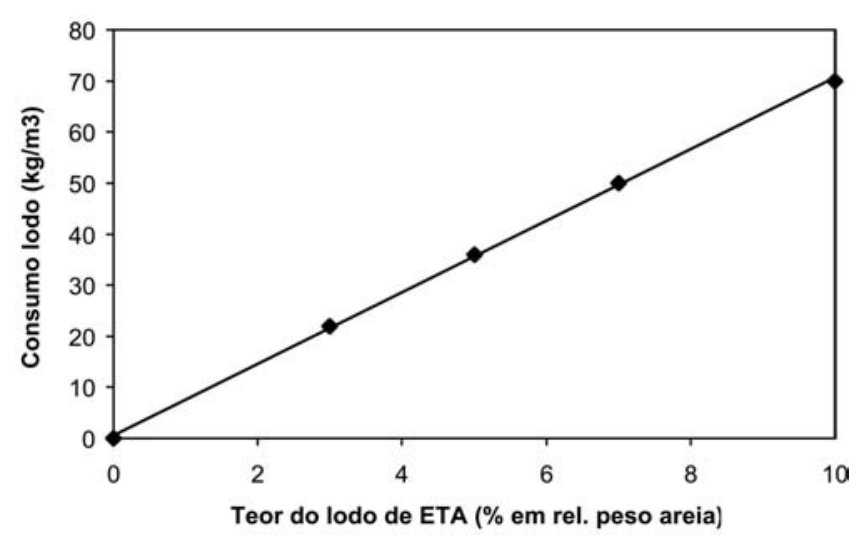

Figura 4: Consumo de lodo de ETA em função do teor de lodo utilizado.

[Figure 4: Sludge consumption as a function of the sludge content.]

nas demais propriedades dos concretos, uma vez que os teores absolutos são bastante pequenos (não passam de $2 \%$ ).

\section{Corpos-de-prova}

Analisando-se superficialmente os cp's, observou-se que apenas aqueles conformados com o traço com $10 \%$ de lodo apresentaram grandes quantidades de ninhos de concretagem ("bicheiras"). Os cp's dos demais traços não demonstraram defeitos.

\section{Resistência à compressão axial simples}

Na Tabela VI estão os resultados de resistência à compressão axial simples, obtida aos 7 e aos $28 \mathrm{~d}$ a partir da moldagem. Os dados expressos referem-se ao valor médio das resistências obtidas de três rupturas, para cada idade e dosagem.

A variação da resistência à compressão em função do aumento do teor de lodo está mostrada na Fig. 5. Observase um decréscimo substancial no valor resultante com o incremento da quantidade de lodo. Pelos coeficientes angulares das curvas, verifica-se que a maior perda de resistência, em relação ao concreto-referência, foi obtida para o traço com $10 \%$ de lodo de ETA. Este fato pode ter sido conseqüência direta da grande quantidade de defeitos nos cp's, em virtude da dificuldade de adensamento. Para os demais teores de lodo (até 7\%), a redução da resistência foi menor, sendo de $18 \%$, aos 7 d, e próxima de $25 \%$, aos 28 d.

Comparando-se as tensões de ruptura dos traços contendo lodo com a do concreto-referência, conforme mostrado na Fig. 6, observa-se que, mesmo aos $7 \mathrm{~d}$, a resistência à compressão já atinge valores acima de $20 \mathrm{MPa}$, exceto para a dosagem com $10 \%$ de lodo. Considerando apenas os valores de resistência mecânica, pode-se direcionar o uso das misturas incorporando até $5 \%$ de lodo, cujas resistências resultaram acima de $30 \mathrm{MPa}$, aos $28 \mathrm{~d}$, em aplicações normais e produção de artefatos de concreto armado. Porém, antes disso, deve-se proceder à realização de outros

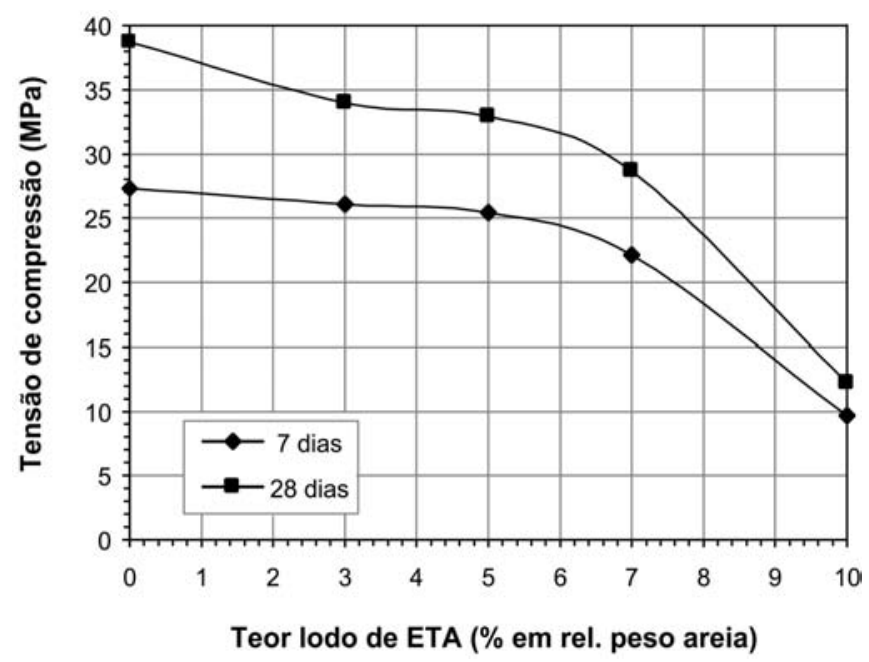

Figura 5: Resistência à compressão do concreto em termos do teor de lodo.

[Figure 5: Compressive strength of concrete according to the contents of the sludge from WTP.]

Tabela VI - Resultados de resistência à compressão.

[Table VI - Results of compressive strength.]

\begin{tabular}{llllll}
\hline Teor de lodo ETA (em relação ao peso de areia) & $0 \%$ & $3 \%$ & $5 \%$ & $7 \%$ & $10 \%$ \\
\hline Resistência aos 7 d (MPa) & 27,3 & 26,1 & 25,4 & 22,1 & 9,7 \\
Resistência aos 28 d (MPa) & 38,7 & 34,0 & 32,9 & 28,7 & 12,2 \\
\hline
\end{tabular}




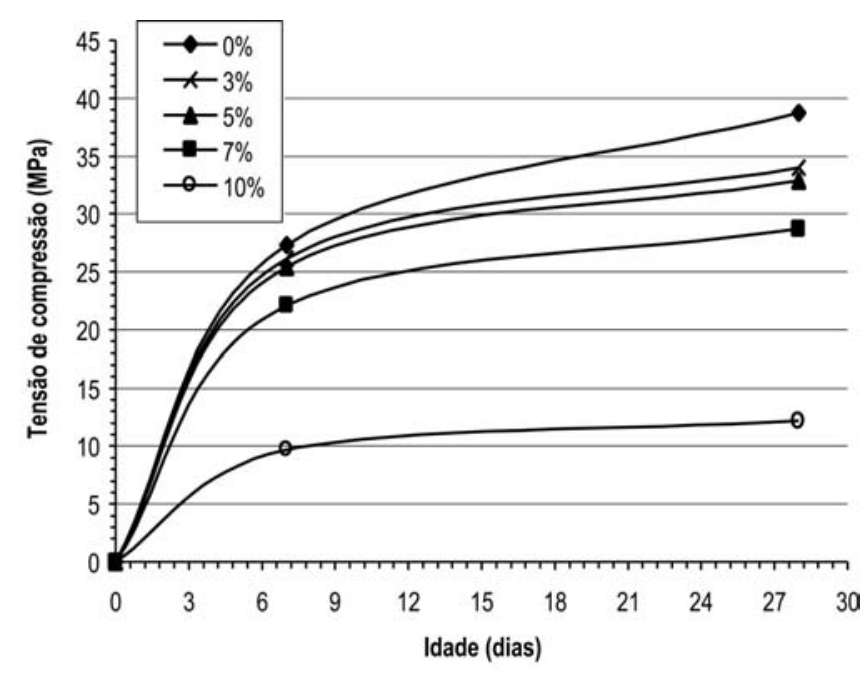

Figura 6: Resistência à compressão do concreto em função da idade.

[Figure 6: Compressive strength of concrete according to the age.]

ensaios mecânicos e de durabilidade. Os demais concretos (teores acima de 5\%) podem ser utilizados em contrapisos, blocos e placas de vedação, peças decorativas, dentre outras aplicações de caráter não-estrutural.

\section{Ensaios físicos em amostras de concreto}

Os valores de absorção de água, massa específica e índice de vazios, obtidos em função do teor de incorporação de lodo, estão reunidos na Tabela VII. Os valores apresentados entre parênteses para o teor de absorção de água referem-se à metodologia proposta pela NBR 6124/80 [53]. Os demais valores correspondem aos critérios da NBR 9778/87 [54], a qual foi utilizada como referência para o ensaio, utilizando-se

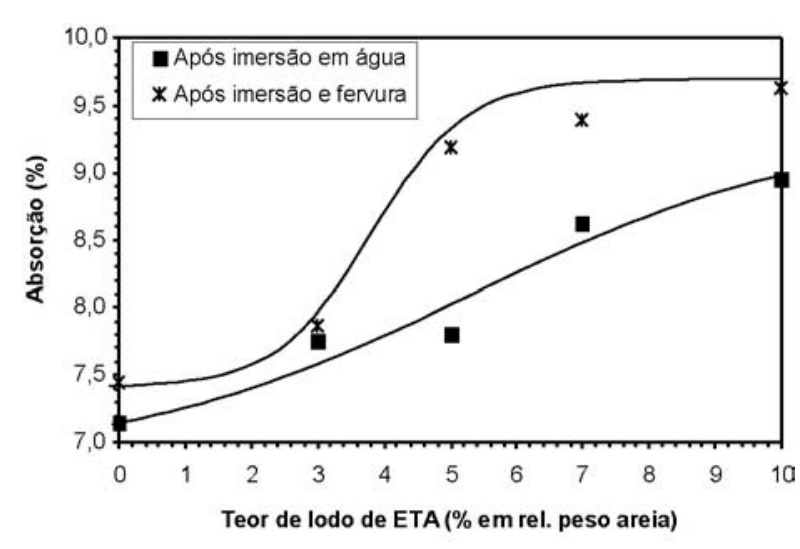

Figura 7: Teor de absorção d'água do concreto em função do teor de lodo.

[Figure 7: Water absorption of concrete as a function of sludge content.]

o recurso da fervura dos corpos-de-prova.

Na Fig. 7 está apresentada a curva resultante do teor de absorção de água. Pode-se verificar que a absorção aumenta consideravelmente com o incremento da quantidade de lodo na massa, o que delimita a durabilidade frente a ambientes agressivos, uma vez que propicia o ingresso de elementos prejudiciais ao concreto, como por exemplo os íons cloreto e sulfato.

Para artefatos de concreto armado para redes de distribuição de energia, a norma NBR 8452/98 [55] limita a absorção de água do concreto (obtida conforme NBR 6124/80 [53]) em 6\%. Este valor, determinado segundo os procedimentos da norma NBR 9778/87 [54], passa a ser de, aproximadamente, $8 \%$. Adotando este último critério para verificação da qualidade dos concretos, pode-se constatar que as misturas que incorporaram $5 \%$ ou mais de lodo não estariam em conformidade com a norma. Entretanto, para

Tabela VII - Resultados dos ensaios físicos nos concretos endurecidos.

[Table VII - Results of the physical tests of hardened concretes].

\begin{tabular}{llllll}
\hline Teor de lodo ETA (\% peso areia) & $0 \%$ & $3 \%$ & $5 \%$ & $7 \%$ & $10 \%$ \\
\hline Absorção (\%) & & & & & \\
Após imersão em água & 7,14 & 7,76 & 7,80 & 8,62 & 8,94 \\
& $(5,37)$ & $(5,83)$ & $(5,86)$ & $(6,48)$ & $(6,72)$ \\
Após imersão e fervura & 7,44 & 7,87 & 9,18 & 9,39 & 9,63 \\
& $(5,59)$ & $(5,92)$ & $(6,90)$ & $(7,06)$ & $(7,24)$ \\
\hline Massa específica (mg.m-3) & & & & & \\
Real & 2,70 & 2,54 & 2,54 & 2,53 & 2,54 \\
Seca & 2,25 & 2,12 & 2,06 & 2,05 & 2,05 \\
Após saturação & 2,41 & 2,28 & 2,22 & 2,22 & 2,23 \\
Após saturação e fervura & 2,42 & 2,28 & 2,25 & 2,24 & 2,24 \\
\hline Índice de vazios (\%) & & & & & \\
Após saturação & 16,13 & 16,40 & 16,51 & 17,87 & 18,45 \\
Após saturação e fervura & 16,72 & 17,62 & 19,26 & 19,52 & 19,95 \\
\hline
\end{tabular}



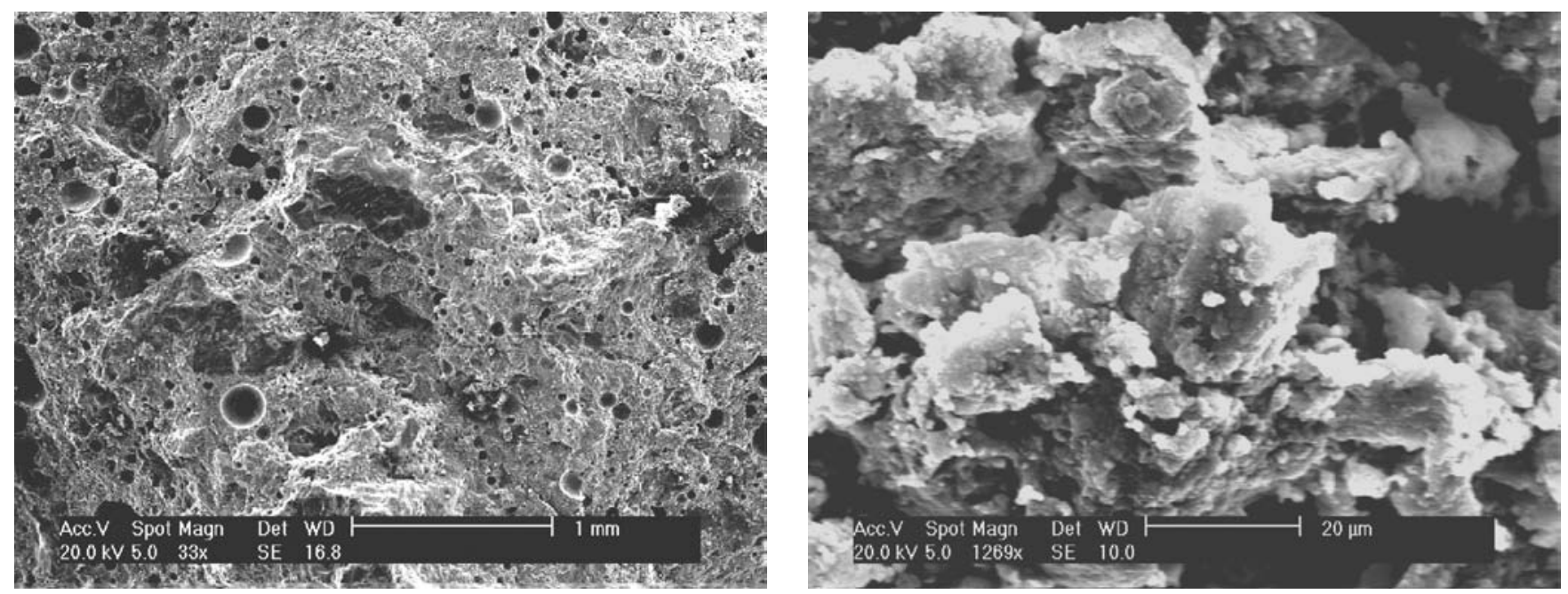

Figura 8: Micrografias da superfície de fratura de cp de concreto com 4\% de lodo, obtidas por microscopia eletrônica de varredura. [Figure 8: Scanning electron microscope images of fracture surface of concrete specimen with $4 \%$ of WTP sludge.]

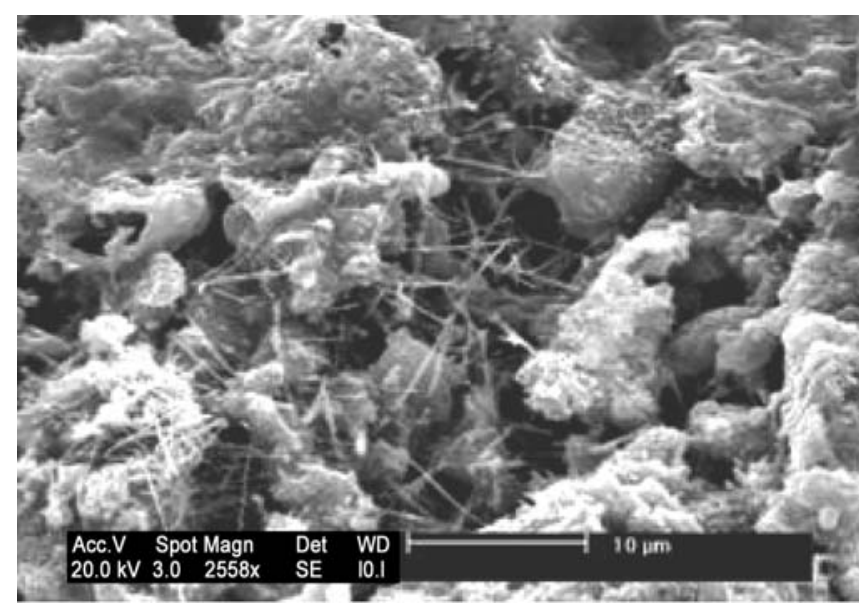

Figura 9: Micrografia da superfície de fratura de cp de concreto com $4 \%$ de lodo, por microscopia eletrônica de varredura, mostrando a presença de etringita.

[Figure 9: Scanning electron microscope image from fracture surface of concrete specimen with $4 \%$ of WTP sludge, showing ettringite phase.]

utilização em concreto convencional (sem armadura), não haveria impedimento de se utilizar os demais traços estudados, considerando-se unicamente o fator absorção de água.

Conforme mostrado na Tabela VII, o índice de vazios, juntamente com o teor de absorção d'água, também apresentou elevação acentuada dos valores para teores de lodo acima de 5\%, após saturação e fervura. A explicação mais provável para esse aumento significativo vem do fato de que parte das partículas do argilomineral que não reagiram com os constituintes do cimento pelo efeito pozolânico, possuindo área superficial considerável, passam a adsorver grandes quantidades de água na sua superfície (o grupo caulinita possui uma área superficial da ordem de $10 \mathrm{~m}^{2} \cdot \mathrm{g}^{-1}$ [41]). Outra hipótese inicialmente considerada foi a dissolução de parte da composição do argilomineral, mas a mesma foi descartada após ensaios de lixiviação e testes químicos da água percolada [16].

Em relação à massa específica, houve redução entre 5,9\% e $8,9 \%$ nos valores apresentados pela composição contendo $10 \%$ de lodo, em comparação com o concreto-referência. Entretanto, a maior variação ocorreu para a mistura com $3 \%$ do material, uma vez que a partir deste teor o decréscimo foi praticamente linear e quase nulo. A redução da massa específica é decorrente da menor densidade do lodo bruto, em comparação à da areia e, também, da presença de vazios, conforme pode ser observado nas imagens da Fig. 8, obtidas por microscopia eletrônica de varredura. Na maioria das imagens obtidas por MEV, e nas respectivas análises por microssonda analítica de raios $\mathrm{X}$, não foi possível identificar fases químicas e microestruturas incomuns à massa de concreto. Porém, um dos cp's com $4 \%$ de lodo de ETA, revelou a presença de agulhas de etringita, conforme mostrado na Fig. 9. Tal fase pode ser conseqüencia de uma reação química devida à presença residual de íon sulfato proveniente do coagulante utilizado, bem como de outros constituintes da argamassa (como por exemplo a gipsita), com o $\mathrm{C}_{3} \mathrm{~A}$ presente no concreto $[40,42,52]$.

\section{CONCLUSÕES}

A análise conjunta dos dados e resultados permite concluir que, nas condições e parâmetros adotados, os traços de concreto contendo até $5 \%$ de lodo podem ser aplicados em situações que vão desde a fabricação de artefatos, blocos e peças de concreto (como placas de estai para redes de distribuição de energia elétrica, tampas de concreto para coberturas de fossas e caixas de passagem, e pedestais para 
apoio de equipamentos) até a construção de pavimentos em concreto de cimento Portland (pavimento rígido). Para teores acima deste, a sua utilização restringe-se a aplicações em que a trabalhabilidade não é um parâmetro primordial como: contrapisos, blocos e placas de vedação, peças decorativas, calçadas e pavimentos residenciais, entre outras. Verificouse, também, que a baixa resistência do traço contendo $10 \%$ de lodo foi resultado, provavelmente, da elevada consistência, a qual comprometeu o adensamento e a qualidade dos corpos de prova. Apesar de ocorrer redução na qualidade do concreto com a incorporação do lodo de ETA, sua utilização como forma de imobilização e co-disposição do resíduo pode ser considerada interessante do ponto de vista ambiental. Constatou-se que a adição do lodo de ETA em matrizes de concreto é uma alternativa viável e ambientalmente correta, uma vez que promove redução de quantidades consideráveis deste material a serem dispostas em aterros ou devolvidas a cursos d'água, bem como reduções significativas no consumo de agregados naturais e, principalmente, de cimento.

\section{AGRADECIMENTOS}

Os autores agradecem ao LACTEC, à SANEPAR, ao Programa de Pós-Graduação em Engenharia de Recursos Hídricos e Ambiental da UFPR e à CAPES, pela infra-estrutura e apoio financeiro para a execução deste projeto de pesquisa.

\section{REFERÊNCIAS}

[1] M. I. Aguilar, Water Res. 36 (2002) 2910-2919.

[2] ABNT, Resíduos sólidos - Classificação, NBR 10.004, Rio de Janeiro (1987).

[3] J. S. Cordeiro, Anais da ABES, RIMA, Rio de Janeiro (2001) 121-142.

[4] F. Bidone, A. P. Silva, D. da M. Marques, Anais da ABES, RIMA, Rio de Janeiro (2001) 215-244.

[5] M. T. Tsutiya, A. Y. Hirata, Anais do Congresso Brasileiro de Engenharia Sanitária e Ambiental, ABES, João Pessoa (2001) 21, cd rom.

[6] AWWA, An assessment of cropland application of water treatment residuals. USA: AWWARF (1995).

[7] S. Y. Luciano, Anais do XXVI Congresso Interamericano de Ingenieria Sanitária y Ambiental, Lima, Peru (1998) cd rom.

[8] AWWA, Land application of water treatment sludge: Impact and management. USA: AWWARF (1990).

[9] C. A. Richter, Tratamento de lodo de estação de tratamento de água, Editora Edgard Blücher Ltda., S. Paulo (2001).

[10] R. M. Barbosa, J. Povinelli, O. Rocha, E. L. G. Espíndola, Anais do XXVII Congresso Interamericano de Ingenieria Sanitaria y Ambiental, Porto Alegre (2000) cd rom.

[11] M. A. P. Reali, Anais da ABES, Rio de Janeiro (1999) 21-40.

[12] E. Lenzi, E. M. Nogami, D. Galli, M. M. Morales, Anais do Congresso Brasileiro de Engenharia Sanitária e Ambiental, Joinville, Brasil (2003) cd rom.

[13] A. P. Silva, F. R. A. Bidone, D. M. L. da M. Marques, Anais do XXVII Congresso Interamericano de Ingenieria
Sanitária Y Ambiental, Porto Alegre, Brasil, (2000) cd rom. [14] S. R. Teixeira, S. A. de Souza, N. R. de Souza, A. E. Job, H. M. Gomes, J. F. Heitzmann Neto, Anais do XXVIII Congresso Interamericano de Ingenieria Sanitária Y Ambiental, Cancún, México, (2002) cd rom.

[15] A. Sales, J. S. Cordeiro, RIMA, ABES, PROSAB (2001) 245-257.

[16] C. Hoppen, Reciclagem de Lodo de ETA Centrifugado na construção civil, Método alternativo de preservação ambiental. Dissertação de Mestrado, Engenharia de Recursos Hídricos e Ambiental, UFPR, Curitiba, PR (2004).

[17] ABNT, Determinação da composição granulométrica dos agregados, NBR 7217, Rio de Janeiro (1987).

[18] ABNT, Agregados - Determinação do teor de argila em torrões e materiais friáveis, NBR 7218, Rio de Janeiro (1987).

[19] ABNT, Agregados - Determinação do teor de materiais pulverulentos NBR 7219, Rio de Janeiro (1987).

[20] ABNT, Agregado em estado solto - Determinação da massa unitária, NBR 7251, Rio de Janeiro (1982).

[21] ABNT, Agregados - Determinação da massa específica de agregados miúdos por meio do frasco de chapman, NBR 9776, Rio de Janeiro (1987).

[22] ABNT, Agregado miúdo - Determinação da absorção de água, NBR NM 30, Rio de Janeiro (2001).

[23] ABNT, Agregado miúdo - Determinação das impurezas orgânicas, NBR NM 49, Rio de Janeiro (2001).

[24] ABNT, Agregado em estado compactado e seco Determinação da massa unitária, NBR 7810, Rio de Janeiro (1983).

[25] ABNT, Determinação da absorção e da massa específica e do teor de ar pelo método gravimétrico, NBR 9937, Rio de Janeiro (2001).

[26] ABNT, Cimento Portland - Determinação da perda ao fogo, NBR 5743, Rio de Janeiro (1989).

[27] ABNT, Cimento Portland - Determinação de resíduo insolúvel, NBR 5744, Rio de Janeiro (1989).

[28] ABNT, Cimento Portland - Determinação do anidrido sulfúrico, NBR 5745, Rio de Janeiro (1989).

[29] ABNT, Cimento Portland - Determinação de óxido de sódio e óxido de potássio por fotometria de chama, NBR 5747, Rio de Janeiro (1989).

[30] ABNT, Cimento Portland - Determinação de óxido de cálcio livre pelo etileno glicol, NBR 7227, Rio de Janeiro (1989).

[31] ABNT, Cimento Portland e outros materiais em pó Determinação da finura por meio da peneira 325, NBR 9202, Rio de Janeiro (1985).

[32] ABNT, Cimento Portland comum e clínquer - Análise química por complexometria, NBR 9203, Rio de Janeiro (1985). [33] ABNT, Cimento Portland pozolânico, Cimento Portland comum e cimento Portland composto com adições de materiais pozolânicos - Análise química - Método de referência, NBR MB 1866, Rio de Janeiro (1991).

[34] ABNT, Cimento Portland - Determinação da finura por meio da peneira de 75 micrometros (Número 200), NBR 11579, Rio de Janeiro (1991).

[35] ABNT, Cimento Portland - Determinação dos tempos de 
pega - Método de ensaio, NBR 11581, Rio de Janeiro (1991). [36] ABNT, Cimento Portland - Determinação da expansibilidade de Le Chatelier, NBR 11582, Rio de Janeiro (1991).

[37] ABNT, Cimento Portland e outros materiais em pó - Determinação da massa específica, NBR NM 23, Rio de Janeiro (2001).

[38] ABNT, Cimento Portland - Determinação da finura pelo método de permeabilidade ao Ar (Método de Blaine), NBR NM 76, Rio de Janeiro (1998).

[39] ABNT, Cimento Portland - Determinação da resistência à compressão, NBR 7215, Rio de Janeiro (1996).

[40] P. K. Mehta, P. J. M. Monteiro, Concreto: estrutura, propriedades e materiais, Editora PINI, S. Paulo (1994).

[41] P. S. Santos, Ciência e tecnologias de argilas. Editora PINI Ltda. $2^{\text {a }}$ edição, Vol. 1, S. Paulo (1997).

[42] A. M. Neville, Propriedades do concreto. Trad. S. E. Giammusso. $2^{\mathrm{a}}$ edição, Editora PINI Ltda., S. Paulo (1997).

[43] ABNT, Concreto - Determinação do teor de ar em concreto fresco, NBR NM 47, Rio de Janeiro (1998).

[44] ABNT, Concreto - Determinação da consistência pelo abatimento do tronco de cone, NBR NM 67, Rio de Janeiro (1998).

[45] ABNT, Concreto Fresco - Determinação da massa específica de agregado miúdo por meio do frasco de Chapman, NBR 9833, Rio de Janeiro (1987).

[46] ABNT, Moldagem e cura de corpos-de-prova cilíndricos ou prismático de concreto, NBR 5738, Rio de Janeiro (1994).
[47] ABNT, Concreto - Ensaio de compressão de corposde-prova cilíndricos - Método de ensaio, NBR 5739, Rio de Janeiro (1994).

[48] ABNT, Argamassa e concreto endurecidos Determinação da absorção de água por imersão - Índice de vazios e massa específica, NBR 9778, Rio de Janeiro (1987).

[49] ABNT, Agregado para concreto - Especificação, NBR 7211, Rio de Janeiro (1983).

[50] P. J. Monteiro, K. Shomglin, H. R. Wenk, N. P. Hasparyk, ACI Mater. J. 179 (2001).

[51] H. F. W. Taylor, Cement Chemistry, Academic Press, New York (1990).

[52] K. L. Scrivener, J. F. Young, ed., Mechanisms of Chemical Degradation of Cement-based Systems, $1^{\text {st }}$ ed., E \& FN Spon, London (1997).

[53] ABNT, Determinação da elasticidade, carga de ruptura, absorção de água e da espessura do cobrimento em postes e cruzetas de concreto armado, NBR 6124, Rio de Janeiro (1980).

[54] ABNT, Argamassa e concreto endurecidos - Determinação da absorção de água por imersão - Índice de vazios e massa específica, NBR 9778, Rio de Janeiro (1987).

[55] ABNT, Postes de concreto armado para redes de distribuição de energia elétrica - Padronização, NBR 8452, Rio de Janeiro (1998).

(Rec. 08/04/04, Rev. 28/05/04, Rev. 11/02/05, Ac. 31/03/05) 